\title{
A mouse model of human repetitive mild traumatic brain injury
}

\author{
Michael J. Kane ${ }^{a, b, \S}$, Mariana Angoa Pérez ${ }^{a, b, \S}$, Denise I. Briggs ${ }^{a, b}$, David C. Viano ${ }^{c, d}$, \\ Christian W. Kreipke ${ }^{b, e}$, and Donald M. Kuhn ${ }^{a, b},{ }^{*}$ \\ aDepartment of Psychiatry \& Behavioral Neurosciences, Wayne State University School of \\ Medicine, Detroit, Michigan 48201-1916 USA \\ bJohn D. Dingell VA Medical Center, Research \& Development Service, Detroit, Michigan \\ 48201-1916 USA \\ 'ProBiomechanics LLC, Bloomfield Hills, Michigan 483042952 USA \\ dDepartment of Biomedical Engineering, School of Engineering, Wayne State University, Detroit, \\ Michigan 48201-1916 USA \\ eDepartment of Anatomy \& Cell Biology, Wayne State University School of Medicine, Detroit, \\ Michigan 48201-1916 USA
}

\section{Abstract}

\begin{abstract}
A novel method for the study of repetitive mild traumatic brain injury (rmTBI) that models the most common form of head injury in humans is presented. Existing animal models of TBI impart focal, severe damage unlike that seen in repeated and mild concussive injuries, and few are configured for repetitive application. Our model is a modification of the Marmarou weight drop method and allows repeated head impacts to lightly anesthetized mice. A key facet of this method is the delivery of an impact to the cranium of an unrestrained subject allowing rapid acceleration of the free-moving head and torso, an essential characteristic known to be important for concussive injury in humans, and a factor that is missing from existing animal models of TBI. Our method does not require scalp incision, emplacement of protective skull helmets or surgery and the procedure can be completed in 1-2 minutes. Mice spontaneously recover the righting reflex and show no evidence of seizures, paralysis or impaired behavior. Skull fractures and intracranial bleeding are very rare. Minor deficits in motor coordination and locomotor hyperactivity recover over time. Histological analyses reveal mild astrocytic reactivity (increased expression of GFAP) and increased phospho-tau but a lack of blood-brain-barrier disruption, edema and microglial activation. This new animal model is simple and cost-effective and will facilitate characterization of the neurobiological and behavioral consequences of rmTBI. It is also ideal for high throughput screening of potential new therapies for mild concussive injuries as experienced by athletes and military personnel.
\end{abstract}

\section{Keywords}

traumatic brain injury; mild; repetitive; concussive; head acceleration; tauopathy

"Corresponding author at: John D. Dingell VA Medical Center, Research \& Development Service, 4646 John R, Detroit, MI 48201-1916, USA, donald.kuhn@wayne.edu (D.M. Kuhn). .

$\S$ These two authors contributed equally

Publisher's Disclaimer: This is a PDF file of an unedited manuscript that has been accepted for publication. As a service to our customers we are providing this early version of the manuscript. The manuscript will undergo copyediting, typesetting, and review of the resulting proof before it is published in its final citable form. Please note that during the production process errors may be discovered which could affect the content, and all legal disclaimers that apply to the journal pertain. 


\section{Introduction}

Traumatic brain injury (TBI) results from a blow to the head. The severity of injury can range along a continuum from mild (e.g., brief change in mental status, somatic effects or consciousness) to severe (e.g., extended unconsciousness, coma, prolonged amnesia) to fatal. Any form of TBI can result in short- and long-term disability. On a global scale, TBI is a serious health concern and is the leading cause of mortality and disability among individuals in high-income countries. TBI is one of the most common neurological diagnoses in the US (Rutland-Brown et al., 2006) and the CDC has estimated that 1.7 million people sustain TBI on an annual basis.

Perhaps the form of TBI that has garnered the greatest scrutiny recently, in the public eye as well as within military, scientific and medical communities, is repetitive, mild TBI (rmTBI). Military operations in Iraq and Afghanistan are revealing that TBI accounts for about 28\% of all combat casualties (Okie, 2005) and approximately $88 \%$ of those are closed-head injury (US Medicine, May 2006, vol. 42). The US Defense and Veterans Brain Injury Center has estimated that $\sim 180,000$ military service members have been diagnosed with mTBI from 2001-2010 and other estimates place this number as high as 320,000 (Tanielian and Jaycox, 2008). Persistent accounts of rmTBI suffered by athletes (amateur and professional) have also directed much needed attention to this growing and significant problem. It has been estimated that 1.6-3.8 million sports-related TBIs occur each year (Guskiewicz et al., 2000; Halstead and Walter, 2010). Epidemiological studies reveal that about $60 \%$ of retired professional football players sustained at least 1 concussion during their careers (Guskiewicz et al., 2005) and approximately 25\% experienced repeat injury (Guskiewicz et al., 2005; Pellman et al., 2004).

RmTBI generally produces a constellation of symptoms (e.g., headache, dizziness, confusion) collectively referred to as post-concussive syndrome (Halstead and Walter, 2010; Pellman et al., 2003b). Reports of more serious consequences of rmTBI such as chronic traumatic encephalopathy (McKee et al., 2009; McKee et al., 2010; Omalu et al., 2010) and increased co-morbidity of neurodegenerative disorders are also emerging (Chen and D'Esposito, 2010; Guskiewicz et al., 2007a; Masel and DeWitt, 2010; Plassman et al., 2000). The situation with regard to rmTBI is made even more complex by the fact that it is extremely difficult to detect. For the most part, routine imaging approaches (e.g., CT and MRI) contribute little to the evaluation and management of mild concussion (Van Boven et al., 2009) but more advanced and specialized approaches such as diffusion tensor imaging are showing promise (Levin et al., 2010; Mac Donald et al., 2011).

The availability of an animal model of rmTBI would certainly facilitate a better understanding of the neurobiological and behavioral outcomes of rmTBI. A large number of animal models of TBI have been developed and these have been effective in characterizing the molecular and cellular bases of acute, severe (i.e., single-impact) TBI (Cernak, 2005; Finnie, 2001; LaPlaca et al., 2007; Lighthall et al., 1989; Long et al., 2009; Morales et al., 2005; Park et al., 1999; Weber, 2007). Biomechanical analyses of head impacts sustained by athletics have revealed that the most critical factors in producing mild, concussive brain injuries are high velocity impact and rapid head acceleration (Guskiewicz et al., 2007b; Meaney and Smith, 2011; Pellman et al., 2003a; Pellman et al., 2003b; Viano et al., 2007; Viano et al., 2005; Viano et al., 2009; Viano and Pellman, 2005). Unfortunately, most existing animal models do not achieve these factors (see (Viano et al., 2009) for discussion). The original Marmarou acceleration weight drop model (Marmarou et al., 1994) causes severe compressive deformation of the cranial vault and results in cortical injuries (e.g., contusions and bleeding) beneath the site of impact. It is also characterized by a high incidence of brainstem injury that can lead to transient hypertension, prolonged apnea, 
respiratory failure and mortality (Cernak, 2005; Chen et al., 1996; Flierl et al., 2009; Kilbourne et al., 2009; Schumann et al., 2008; Stahel et al., 2000). Highly effective methods for producing mild, closed-head injuries have been employed in the study of single impacts (Milman et al., 2005; Zohar et al., 2003). TBI models other than closed-head, to include lateral fluid percussion (Thompson et al., 2005) and controlled cortical impact (Lighthall et al., 1989) involve direct loading of the brain and do not impart rapid changes in head acceleration (i.e., subject heads are fixed in a stereotaxic frame) making them less than ideal to recapitulate the kinds of injury seen after rmTBI in humans. Because the vast majority of existing animal models of TBI impart such severe injuries with single impacts, it is difficult to study repetitive injuries using them. Results from those attempts to apply multiple injuries (usually 2) have been somewhat inconsistent in finding that by comparison to single injuries, multiple insults worsen (Hamberger et al., 2009; Kanayama et al., 1996; Laurer et al., 2001; Longhi et al., 2005; Uryu et al., 2002), make little difference (Creeley et al., 2004; DeFord et al., 2002) or actually improve outcome (DeRoss et al., 2002). We report presently a new mouse model that makes possible the study the human form of rmTBI.

\section{Materials and methods}

\subsection{Apparatus and application of the method of $\mathrm{rmTBI}$}

The essential components and overall arrangement of the rmTBI apparatus are shown in Fig. 1. Weights (19 mm diameter) were milled from solid brass to the desired mass (e.g., 60, 75, $95,120 \mathrm{~g}$ ) by varying their length but the $95 \mathrm{~g}$ weight was the only one used presently for impacting the mouse skull. This initial weight was estimated from the ratio of mouse to rat brain weights $(\sim 0.21)$ to scale down from the $450 \mathrm{~g}$ weight used with rats in the Marmarou method (Kreipke et al., 2006). A small steel cap $(2 \times 10 \mathrm{~mm})$ is glued to the bottom of the weight to restrict the zone of contact to the top of the mouse head between the ears. Weights are dropped vertically through a PVC guide tube ( $20 \mathrm{~mm}$ diameter $\times 1.5$ meter length). The vertical traverse of the dropped weight is limited to $40 \mathrm{~mm}$ of impact displacement by Orvis Super Strong knotless tapered leader (5X), commercially available nylon fly fishing line (2.2 kg test, $0.53 \mathrm{~mm}$ diameter). A stage consisting of a slit piece of aluminum foil, held in place by an "H"-shaped Plexiglas frame $(15 \mathrm{~cm}$ length $\times 9 \mathrm{~cm}$ width $\times 23 \mathrm{~cm}$ depth) holds subjects in place. In this fashion, the slit foil just supports the body weight of a mouse $(22-25 \mathrm{~g})$ with little or no resistance or restraint upon impact. A sponge cushion $(15 \mathrm{~cm}$ length $\times 9 \mathrm{~cm}$ width $\times 13 \mathrm{~cm}$ depth) is located $10 \mathrm{~cm}$ below the aluminum foil stage to receive the falling mouse while the weight remains tethered above the free-moving body of the animal. A photograph showing the dimensions of the foil stage and placement of an anesthetized mouse on it is included as Supplementary Figure 1. In some experiments, the new rmTBI method was compared to the original Marmarou method (Marmarou et al., 1994) by resting mice directly on the sponge cushion. Immediately upon impact, mice were withdrawn to prevent re-hits by the weight as subjects recoiled from the impact-induced compression of the cushion causing secondary injuries to the brain and spinal cord.

All procedures involving the use of animals in this study were reviewed and approved by the Wayne State University Institutional Animal Care and Use Committee. Mice are lightly anesthetized with isoflurane (i.e., until unresponsive to paw or tail pinch) and placed immediately under the vertical PVC tube. Mice are suspended chest-down on a slit piece of aluminum foil $10 \mathrm{~cm}$ above a foam cushion. The mouse is quickly positioned so that its head is directly in the path of the falling weight by first resting the weight on the scalp midline between bregma and lambda. Incisions in the scalp or emplacement of a protective skull helmet are not necessary. The weight is then pulled rapidly upward by an attached string to the desired drop distance and released. The downward traverse of the falling weight is restricted by the string such that upon contact, the weight travels no more than $1 \mathrm{~cm}$ beyond the original position of the dorsal surface of the head. Immediately upon impact, the mouse 
falls freely onto the foam cushion. In this arrangement, the impact-induced acceleration and fall always involves a $180^{\circ}$ horizontal rotation of the mouse body. The mouse is moved immediately to a holding cage to recover. A short video clip of the method is included as Supplementary Material for online presentation. As part of the initial and preliminary validation of our method, mice were exposed to 1,5 (1 per day for 5 successive days) or 10 ( 1 per day for 5 days with a 2 day rest after the $5^{\text {th }}$ ) impacts (specified below) using a single weight $(95 \mathrm{~g})$ dropped from 1 meter. The time after exposure to injury at which outcome tests were carried out are specified below in the results section. A total of 327 mice were used in this study and the numbers used in each experiment are specified in the figure legends.

\subsection{Neurological and behavioral assessment}

2.2.1. Edema-Edema was determined as brain water content using the wet/dry method as previously described (Kawai et al., 2001; Masada et al., 2001). Mice were decapitated and brains were rapidly removed from the skull. Whole, fresh brain was weighed on aluminum foil, dried for 72 hours at $80^{\circ} \mathrm{C}$ in a Personal Hyb hybridization oven (Strategene, La Jolla, $\mathrm{CA}$ ), and reweighed. Brain water content was defined as \% of water calculated as (wet weight - dry weight $) /($ wet weight $) \times 100$.

2.2.2. Recovery of righting reflex-Immediately following the weight-drop impact, mice were placed on their backs in a clean cage. Controls were anesthetized but not subjected to head impact. Righting reflex response was evaluated as an indicator of neurologic restoration. The time taken by injured and control mice to adopt a prone position following injury or anesthesia was recorded by 3 observers blinded to the treatment. The 3 times were averaged for a single score for each subject. Any occurrence of apnea, paralysis, seizure, or death was noted. All mice were acclimated to the test room for $30 \mathrm{~min}$ prior to experimentation using this and all other behavioral assays.

2.2.3. Balance and motor coordination-Balance and motor coordination were tested in all controls (anesthetized, not injured) and injured mice at the prescribed post-injury time points (24hr or $7 \mathrm{~d}$ following the last injury or anesthesia only) using an accelerating rotarod (Ugo Basile, Collegeville, PA). Mice were placed onto the accelerating rod, which gradually increased in rotational speed from $4>40 \mathrm{rpm}$ over $5 \mathrm{~min}$, and remained on until they fell off or reached the maximum time ( 300 seconds). Time spent on the apparatus was recorded for each animal.

2.2.4. Locomotor activity-Locomotor activity was measured in four transparent plastic cages (AccuScan Instruments, Columbus, OH; $43 \mathrm{~cm} \times 42 \mathrm{~cm} \times 42 \mathrm{~cm}$ ) each covered by a removable perforated plastic lid. Controls (anesthetized, not injured) and injured mice were placed in the center of the cage and allowed to move freely for 30 minutes. During that time, activity was measured by 16 infrared light beam arrays in the horizontal and vertical axes. Motor activity was recorded on a computer and analyzed by Fusion software (AccuScan). Total activity was defined as the sum of all beam breaks in both horizontal and vertical planes during the 30 min recording session.

\subsection{Immunohistochemical, immunoblotting and histochemical analyses}

\subsubsection{Immunohistochemical staining for GFAP expression-}

Immunohistochemical analyses were carried out as previously described (Angoa-Perez et al., 2010; Thomas et al., 2008b). Mice were deeply anesthetized with pentobarbital (200 mg/ $\mathrm{kg}$, ip) and perfused transcardially with buffered $4 \%$ paraformaldehyde. Sections $(50 \mu \mathrm{m})$ from somatosensory cortex (immediately below the impact site on the skull), piriform cortex and hippocampus, inclusive of sections containing the corpus callosum, were floated in 1 
$\mathrm{ml} /$ well of $\mathrm{PBS} / 3 \% \mathrm{H}_{2} \mathrm{O}_{2}$ for 30 minutes to inactivate endogenous peroxidases. The PBS/ $3 \% \mathrm{H}_{2} \mathrm{O}_{2}$ solution was removed and wells were washed with PBS one time for 5 minutes. Sections were blocked in $500 \mu$ l blocking buffer (PBS, $10 \%$ bovine serum albumin, $3 \%$ Triton $\mathrm{X}-100,1.5 \%$ normal goat serum) for $1 \mathrm{~h}$ at room temperature (RT). The primary antibody, anti-GFAP (1:500; LabVision, Fremont, CA) was diluted in blocking buffer (primary antibody solution). $500 \mu$ l of primary antibody solution was added to each well and incubated at $4{ }^{\circ} \mathrm{C}$ overnight. The next morning, primary antibody solution was removed and each well was washed with $1 \mathrm{ml}$ PBS/0.1\% Triton X-100 three times for 5 minutes each. The biotinylated secondary antibody (Vectastain Elite, Vector Labs, Burlingame, CA) was diluted in blocking buffer (1:1000) and $500 \mu \mathrm{l}$ of this secondary antibody solution was added to each well and incubated for 30 minutes at RT. The secondary antibody solution was removed and each well was washed with $1 \mathrm{ml}$ PBS/0.1\% Triton X-100 three times for 5 minutes each. $500 \mu \mathrm{l}$ of ABC reagent (Vector Labs) was added to each well and incubated for 30 minutes at RT. Each well was washed with $1 \mathrm{ml}$ PBS/0.1\% Triton X-100 three times for 5 minutes each. After the last wash, wells were filled with PBS and incubated for 5 minutes. The PBS was removed and $1 \mathrm{ml}$ DAB staining solution (Vector Labs) was added to each well and incubated for 5-10 min at RT, until sufficient color developed. DAB staining solution was removed and $1 \mathrm{ml}$ PBS was added to each well to stop the DAB reaction. Sections were mounted on Fisher SuperFrost Plus Slides and thoroughly dried. Sections were dehydrated through graded ethanol washes, incubated in Citrisolv for 5 minutes, and coverslipped with Permount. Slides were allowed to dry overnight before viewing.

2.3.2. Immunoblot analysis for GFAP and phospho-tau levels-Immunoblot analyses were carried out as previously described by our lab (Angoa-Perez et al., 2010; Thomas et al., 2009, 2008b). Mice were sacrificed by decapitation and the hippocampus and cortex were dissected bilaterally and stored at $-80^{\circ} \mathrm{C}$. Frozen tissue was disrupted by sonication in $1 \%$ sodium dodecyl sulfate (SDS) at $95^{\circ} \mathrm{C}$ and insoluble material was sedimented by centrifugation $(18,000 \times \mathrm{g})$. Protein concentration was determined by the bicinchoninic acid (BCA) method and equal amounts of protein $(50 \mu \mathrm{g} / \mathrm{lane}$ for both cortex and hippocampus) were resolved by SDS-polyacrylamide gel electrophoresis (SDS-PAGE) and electroblotted to nitrocellulose membranes. Blots were incubated in blocking buffer (Tris-buffered saline containing Tween 20,0.1\% v/v, and 5\% non-fat dry milk) for $1 \mathrm{~h}$ at RT. Primary antibodies directed at GFAP (1:2000; LabVision, Fremont, CA), phospho-tau (1:200; Abcam, Cambridge, MA), or $\beta$-actin (1:2000; Sigma Aldrich, St. Louis, MO) were diluted in blocking buffer and incubated on blots for $16 \mathrm{~h}$ at $4{ }^{\circ} \mathrm{C}$. Blots were subsequently washed 3 times for 5 minutes in TBS/Tween to remove excess primary antibody and incubated with horseradish peroxidase (HRP)-conjugated anti-IgG secondary antibody (1:4000; Sigma Aldrich) diluted in blocking buffer for $1 \mathrm{~h}$ at RT. The blots were washed 3 times for 5 minutes in TBS/Tween to remove excess secondary antibody. Immunoreactive bands were visualized by enhanced chemiluminescence (Western Lightning Plus-ECL, Perkin Elmer, Waltham, MA) on a Kodak Image Station (Carestream Molecular Imaging, New Haven, CT). The relative densities of GFAP and phospho-tau reactive bands were quantified using the Image $J$ software program and normalized to $\beta$-actin.

2.3.3. Histochemical staining for microglial activation-Microglial activation was assessed by histochemical staining of brain sections with Isolectin B4 (ILB 4 ) as previously described in our lab (Thomas et al., 2008a; Thomas et al., 2004). Briefly, $50 \mu \mathrm{m}$ sections (paraformaldehyde fixed) from somatosensory cortex (immediately below the impact site), piriform cortex, and the hippocampus were floated in $1 \mathrm{ml} /$ well of $\mathrm{PBS} / 3 \% \mathrm{H}_{2} \mathrm{O}_{2}$ for 30 minutes to inactivate endogenous peroxidases. Sections were washed once in PBS/0.1\% Triton X-100 for 5 minutes and incubated in fresh PBS/0.1\% Triton X-100 for an additional 30 minutes. Microglia were labeled with HRP-conjugated $\mathrm{ILB}_{4}(10 \mu \mathrm{g} / \mathrm{ml}$ in PBS/0.1\% 
Triton X-100; Sigma Aldrich) overnight at $4^{\circ} \mathrm{C}$. Excess $\mathrm{ILB}_{4}$ was removed by washing with PBS/0.1\% Triton X-100 three times for 5 minutes each. Sections were incubated with the DAB substrate $(0.1 \mathrm{mg} / \mathrm{ml}$ in PBS; Sigma Aldrich) for $25 \mathrm{~min}$. After desired color development, wells were then washed with PBS three times for 5 minutes and sections were mounted on Fisher SuperFrost Plus Slides and thoroughly dried. Sections were dehydrated through a series of graded ethanol washes, incubated in Citrisolv for $5 \mathrm{~min}$, and coverslipped using Permount. Slides were allowed to dry overnight before analysis.

\section{Results}

Exposure of mice to single impacts using our new method revealed that subjects were experiencing very mild injury. Mice recover consciousness spontaneously, show normal grooming and social interactions with cage mates and do not display any signs of pain or discomfort or resistance to handling after the procedure. Skull fractures, intracranial bleeding, respiratory arrest or seizures are rarely seen. Therefore, we tested mice for their responses to 5 impacts delivered one per day for successive days. The general responsiveness of mice to repeated head impact is presented in Table 1. Data in this table confirm that even repeat injury was mild in nature, causing little if any change in the rate of skull fracture or intracranial bleeding by comparison to single impacts. The rate of mortality after single (5\%) or multiple (10\%) impacts was very low by comparison to the high mortality associated with single (64\%) impacts using the original Marmarou method. Attempts to deliver repeated impacts using the original Marmarou were halted when it became evident that mortality exceeded $90 \%$. The incidence of skull fracture and intracranial bleeding, alone or in combination, was substantially lower using our new method by comparison to the original Marmarou. The time required for subjects to recover the righting reflex was measured and the results are presented in Fig. 2. It can be seen that a single impact increased recovery times over controls (anesthetized but not injured) by about 2 minutes. Successive daily head impacts, up to the $5^{\text {th }}$, did not further increase recovery times over the first indicating that the effects of this method of TBI were very mildly concussive. By comparison, the time to recover the righting reflex after a single non-lethal impact using the original Marmarou method can be increased by as much as 15 -fold (Goodman et al., 2011).

The original Marmarou method results in a significant edema (Foda and Marmarou, 1994) so we assessed this outcome in mice $4 \mathrm{hr}$ after a single or 5 separate head impacts. The results in Fig. 3 show that edema does not occur using this new method. Repeated mild concussive injury in humans can result in problems with balance and postural equilibrium (Guskiewicz, 2011) so we tested mice for their performance on the accelerating rotarod test. Fig. 4 shows that a total of 4 head impacts (2/day, $6 \mathrm{hr}$ apart, for 2 days) caused a significant worsening in rotarod performance in injured mice when tested 1 day after the last injury. Conversely, if 5 impacts were delivered (1/day for 5 successive days) and testing was carried out 7 days after the final injury, rotarod performance was not different from controls (anesthetized, not subjected to head impact). Mice exposed to 10 injuries showed mild deficits in the rotarod test at 7 days but this effect was not significantly different from control. Locomotor activity was measured after repeat head impacts and the results are presented in Fig. 5. It can be that 5 head impacts resulted in a significant increase in locomotor activity when assessed 5 days after the last impact but this effect recovered within 30 days.

Histological analyses were consistent with behavioral and neurological outcomes (above) and revealed a mild injury at the cellular level. We did not observe contusions or extensive loss of cortical matter below the point of impact to the skull (data not shown). The integrity of the blood-brain barrier was assessed by measuring intracerebral mouse IgG levels by 
immunohistochemistry and the results in Fig. 6 indicate that barrier integrity was not compromised by 1 (Fig. 6A) or 5 repeated head impacts (Fig. 6B). By comparison, the original Marmarou caused substantial disruption in the blood brain barrier, associated with a rather large cortical contusion beneath the site of skull impact. Increased expression of GFAP in hippocampus and cortex was observed, measured both by immunoblotting and immunohistochemistry. Quantitation of immunoreactive bands in Fig. 7 (upper panels) shows that the increases in GFAP expression in hippocampus and cortex were significantly different from control. Immunohistochemical analyses (lower panels) confirmed increased GFAP after rmTBI in both brain areas. Assessment of microglial activation using histochemical staining with $\mathrm{ILB}_{4}$ was negative when tested 30 days after 5 or 10 head impacts (Fig. 8B,C). Substantial microglial activation was seen throughout hippocampus and overlying cortex (data not shown) when determined in mice 30 days after exposure to a single impact using the original Marmarou method as shown in Fig. 8D. The levels of phospho-tau, a microtubule associated protein, were determined in cortex by immunoblotting because hyper-phosphorylated helical fragments of tau have been associated with neuronal tangles observed in postmortem brain from athletes exposed to repetitive concussive injury (McKee et al., 2009; McKee et al., 2010). Fig. 9 shows that mice exposed to 5 head impacts have significantly higher levels ( $160 \%$ of control) of phospho-tau 30 days after injury by comparison to controls. As a positive control, mice were treated with chloral hydrate (500 $\mathrm{mg} / \mathrm{kg}$, ip) which is known to lead to rapid (60 min) hyperphosphorylation of tau (Planel et al., 2007) and results in Fig. 9 document a 3.5-fold increase in phospho-tau levels.

\section{Discussion}

The purpose of our study was to design and implement a new model of human rmTBI using mice as subjects. Applying simple but crucial modifications to the tried-and-tested Marmarou weight drop method of TBI allowed repeated head impacts resulting in mild concussive injuries. By suspending mice unrestrained on a stage that offers minimal resistance to acceleration of the head upon impact and delivering a blow to the head that is glancing versus crushing, many of the serious outcomes associated with closed-head models of TBI (i.e., high mortality, skull fracture, respiratory arrest) are avoided. Consequently, mice can be exposed readily to 1-2 impacts per day over extended periods of time until a total of at least 10 exposures have been completed. Initial validation of this method establishes that it produces an injury that can be classified as mild. Mortality rates and the incidence of skull fracture and intracranial bleeding are very low. From a behavioral perspective, mice exposed to rmTBI using our model appear normal and do not show any evidence of seizures, paralysis or pain. Injured mice are not aggressive toward their cage mates and they do not resist handling or vocalize when handled to any greater extent than controls.

Consistent with results from athletes who have experienced repeated mild concussive injuries (Guskiewicz, 2011), mice exposed to repeated head impacts using our method do show mild balance and coordination deficits. However, these deficits are not serious enough to interfere with food and water intake, nor do they appear to alter normal grooming. It also appears that deficits seen in repeatedly injured mice on the rotarod test recover over time. Another outcome with high translational relevance that we observed after rmTBI using our new model of rmTBI was a transient increase in locomotor activity. Humans who have experienced TBI, particularly children, often develop secondary problems with attention. These attention deficits involve slowing of information processing speed and response inhibition, and are associated with hyperactivity (Konrad et al., 2000). TBI in rodents can also result in hyperactivity (Homsi et al., 2010; Pullela et al., 2006). Therefore, the present finding of increased locomotor activity after rmTBI is consistent with both clinical and basic 
research reports and provides additional validation of this new model. Another outcome often associated with TBI in humans and in animal models is persistent cognitive dysfunction (Bales et al., 2009). We have not yet systematically evaluated cognitive performance after subjecting mice to rmTBI but this is a high priority analysis that will be the focus of future experiments.

From a histological perspective, repeatedly injured mice do not show edema, cortical contusions or obvious loss of neuronal matter beneath the point of impact on the skull. The blood brain barrier remains intact and attempts to document microglial activation were negative. However, mice subjected to rmTBI do show increased GFAP expression, indicative of a mild astrocytic response to injury. Perhaps of greatest interest were the findings of increased expression of phospho-tau 30 days after the last injury. Increases in phospho-tau and GFAP could be early signs of chronic traumatic encephalopathy, hallmark neuropathological indices that are now being associated with professional athletes exposed to multiple, mild concussive injuries during their careers (McKee et al., 2009; McKee et al., 2010; Omalu et al., 2010). Limited experiments did not reveal evidence of increased $\beta$-APP staining (data not shown) but additional studies will be required to confirm and extend the initial findings reported above.

The key characteristics of this new model that set it apart from other closed head models and make it ideal for studies of rmTBI include the following: a) it can be used to deliver repeated, mild injuries to the same subject; b) the body and head of the subject are not constrained (e.g., not resting on a cushion or fixed in a stereotaxic frame) and the mouse falls freely upon impact; c) the dropped weight does not "drive" the head into a cushion and thereby avoids the additional loading factors and midbrain injuries imparted by it (Viano et al., 2009); d) the falling weight is restricted in the length of its downward traverse (glancing blow, not crushing) and cannot strike the head of the subject multiple times (e.g., after mouse and weight recoil post-impact); e) the impact causes a very rapid and rotational acceleration of the head, an essential characteristic of blows to the head of humans exposed to concussive injuries (Guskiewicz et al., 2007b; Meaney and Smith, 2011; Pellman et al., 2003a; Pellman et al., 2003b; Viano et al., 2007; Viano et al., 2005; Viano et al., 2009; Viano and Pellman, 2005); f) only light anesthesia is required, minimizing the confounding effects of prolonged anesthesia on TBI outcome (Statler et al., 2006) and incisions of the scalp or other surgical preparations (e.g., emplacement of protective skull helmet) are not needed; g) resuscitation and post-injury support (e.g., maintenance of body temperature) are not required as the animals recover the righting reflex spontaneously; $h$ ) the procedure is simple, inexpensive, and rapid (can be carried out in $~ 1-2$ minutes per mouse); (i) it can be applied readily to rats and other rodents, and $\mathrm{j}$ ) it is suitable for high-throughput screening of therapeutic compounds.

The blow to a mouse head using our model, when viewed real-time or in slow-motion video, is fundamentally very similar to that seen in helmet-to-helmet collisions in football, head-tohead collisions in soccer or fist-to-jaw punches in boxing, blows that are now known to cause persistent concussive injury and chronic traumatic encephalopathy, especially when repeated (McKee et al., 2009; McKee et al., 2010; Omalu et al., 2010). These characteristics are difficult to achieve in existing animal models of closed head TBI (i.e., the original Marmarou method and variants) as well as in non-closed head methods such as controlled cortical impact and lateral fluid percussion. RmTBI is emerging as a serious medical and socioeconomic concern on a global scale. In consideration of the fact that very little is known about its neuropathological mechanisms and long-term behavioral consequences, a new and widely applicable animal model is certainly called for. 
In conclusion, we feel that the model of rmTBI, as described in the present manuscript, overcomes the limitations inherent in existing animal models and offers the opportunity for increased understanding of the pathophysiology of repetitive, mild concussive injury to the brain. This unique model will also allow study of the importance of such variables as number and severity of head injuries and their frequency on long-term outcome measures. We have not yet determined "optimal" injury conditions but results using the $95 \mathrm{~g}$ weight suggest that lower weights could be used with multiple impacts per day (e.g., 3-5) to more closely simulate head impact conditions associated with full contact sports. Injury thresholds for mild brain injury have been hard to obtain using existing animal models, for many of the reasons mentioned above, and recent studies in humans using real-time data collection of head impacts indicate that the concussive injury threshold is indeed very difficult to determine and may be irrelevant when relating injury to clinical outcome (Guskiewicz and Mihalik, 2011). The in-depth study of rmTBI in animals has not been that feasible to date but the availability of an appropriate model may help identify new biomarkers of mild concussive injury in humans that are not yet known to exist and are not accessible for characterization and study.

\section{Supplementary Material}

Refer to Web version on PubMed Central for supplementary material.

\section{Acknowledgments}

This research was supported by grants from the NIH and the Department of Veteran's Affairs. We thank the carpentry shop at the John D. Dingell VA Medical Center for its expert assistance in fashioning the brass weights used in these studies.

\section{References}

Angoa-Perez M, Kreipke CW, Thomas DM, Van Shura KE, Lyman M, McDonough JH, Kuhn DM. Soman increases neuronal COX-2 levels: Possible link between seizures and protracted neuronal damage. Neurotoxicology. 2010; 31:738-46. [PubMed: 20600289]

Bales JW, Wagner AK, Kline AE, Dixon CE. Persistent cognitive dysfunction after traumatic brain injury: A dopamine hypothesis. Neurosci Biobehav Rev. 2009; 33:981-1003. [PubMed: 19580914]

Cernak I. Animal models of head trauma. NeuroRx. 2005; 2:410-22. [PubMed: 16389305]

Chen AJ, D'Esposito M. Traumatic brain injury: from bench to bedside to society. Neuron. 2010; 66:11-4. [PubMed: 20399725]

Chen Y, Constantini S, Trembovler V, Weinstock M, Shohami E. An experimental model of closed head injury in mice: pathophysiology, histopathology, and cognitive deficits. J Neurotrauma. 1996; 13:557-68. [PubMed: 8915907]

Creeley CE, Wozniak DF, Bayly PV, Olney JW, Lewis LM. Multiple episodes of mild traumatic brain injury result in impaired cognitive performance in mice. Acad Emerg Med. 2004; 11:809-19. [PubMed: 15289185]

DeFord SM, Wilson MS, Rice AC, Clausen T, Rice LK, Barabnova A, Bullock R, Hamm RJ. Repeated mild brain injuries result in cognitive impairment in B6C3F1 mice. J Neurotrauma. 2002; 19:427-38. [PubMed: 11990349]

DeRoss AL, Adams JE, Vane DW, Russell SJ, Terella AM, Wald SL. Multiple head injuries in rats: effects on behavior. J Trauma. 2002; 52:708-14. [PubMed: 11956388]

Finnie J. Animal models of traumatic brain injury: a review. Aust Vet J. 2001; 79:628-33. [PubMed: 11702936]

Flierl MA, Stahel PF, Beauchamp KM, Morgan SJ, Smith WR, Shohami E. Mouse closed head injury model induced by a weight-drop device. Nat Protoc. 2009; 4:1328-37. [PubMed: 19713954]

Foda MA, Marmarou A. A new model of diffuse brain injury in rats. Part II: Morphological characterization. J Neurosurg. 1994; 80:301-13. [PubMed: 8283270] 
Goodman MD, Makley AT, Huber NL, Clarke CN, Friend LA, Schuster RM, Bailey SR, Barnes SL, Dorlac WC, Johannigman JA, Lentsch AB, Pritts TA. Hypobaric hypoxia exacerbates the neuroinflammatory response to traumatic brain injury. J Surg Res. 2011; 165:30-7. [PubMed: 20850781]

Guskiewicz KM. Balance assessment in the management of sport-related concussion. Clin Sports Med. 2011; 30:89-102. [PubMed: 21074084]

Guskiewicz KM, Marshall SW, Bailes J, McCrea M, Cantu RC, Randolph C, Jordan BD. Association between recurrent concussion and late-life cognitive impairment in retired professional football players. Neurosurgery. 2005; 57:719-26. [PubMed: 16239884]

Guskiewicz KM, Marshall SW, Bailes J, McCrea M, Harding HP Jr. Matthews A, Mihalik JR, Cantu RC. Recurrent concussion and risk of depression in retired professional football players. Med Sci Sports Exerc. 2007a; 39:903-9. [PubMed: 17545878]

Guskiewicz KM, Mihalik JP. Biomechanics of sport concussion: quest for the elusive injury threshold. Exerc Sport Sci Rev. 2011; 39:4-11. [PubMed: 21088602]

Guskiewicz KM, Mihalik JP, Shankar V, Marshall SW, Crowell DH, Oliaro SM, Ciocca MF, Hooker DN. Measurement of head impacts in collegiate football players: relationship between head impact biomechanics and acute clinical outcome after concussion. Neurosurgery. 2007b; 61:1244-52. [PubMed: 18162904]

Guskiewicz KM, Weaver NL, Padua DA, Garrett WE Jr. Epidemiology of concussion in collegiate and high school football players. American J Sports Med. 2000; 28:643-50.

Halstead ME, Walter KD. Sport-Related Concussion in Children and Adolescents. Pediatrics. 2010; 126:597-615. [PubMed: 20805152]

Hamberger A, Viano DC, Saljo A, Bolouri H. Concussion in professional football: morphology of brain injuries in the NFL concussion model--part 16. Neurosurgery. 2009; 64:1174-82. [PubMed: 19487898]

Homsi S, Piaggio T, Croci N, Noble F, Plotkine M, Marchand-Leroux C, Jafarian-Tehrani M. Blockade of acute microglial activation by minocycline promotes neuroprotection and reduces locomotor hyperactivity after closed head injury in mice: a twelve-week follow-up study. $\mathrm{J}$ Neurotrauma. 2010; 27:911-21. [PubMed: 20166806]

Kanayama G, Takeda M, Niigawa H, Ikura Y, Tamii H, Taniguchi N, Kudo T, Miyamae Y, Morihara $\mathrm{T}$, Nishimura T. The effects of repetitive mild brain injury on cytoskeletal protein and behavior. Methods Find Exp Clin Pharmacol. 1996; 18:105-15. [PubMed: 8740242]

Kawai N, Kawanishi M, Okauchi M, Nagao S. Effects of hypothermia on thrombin-induced brain edema formation. Brain Res. 2001; 895:50-8. [PubMed: 11259759]

Kilbourne M, Kuehn R, Tosun C, Caridi J, Keledjian K, Bochicchio G, Scalea T, Gerzanich V, Simard JM. Novel model of frontal impact closed head injury in the rat. J Neurotrauma. 2009; 26:223343. [PubMed: 19929375]

Konrad K, Gauggel S, Manz A, Scholl M. Inhibitory control in children with traumatic brain injury (TBI) and children with attention deficit/hyperactivity disorder (ADHD). Brain injury. 2000; 14:859-75. [PubMed: 11076133]

Kreipke CW, Morgan NC, Petrov T, Rafols JA. Calponin and caldesmon cellular domains in reacting microvessels following traumatic brain injury. Microvasc Res. 2006; 71:197-204. [PubMed: 16635497]

LaPlaca MC, Simon CM, Prado GR, Cullen DK. CNS injury biomechanics and experimental models. Prog Brain Res. 2007; 161:13-26. [PubMed: 17618967]

Laurer HL, Bareyre FM, Lee VM, Trojanowski JQ, Longhi L, Hoover R, Saatman KE, Raghupathi R, Hoshino S, Grady MS, McIntosh TK. Mild head injury increasing the brain's vulnerability to a second concussive impact. J Neurosurg. 2001; 95:859-70. [PubMed: 11702878]

Levin HS, Wilde E, Troyanskaya M, Petersen NJ, Scheibel R, Newsome M, Radaideh M, Wu T, Yallampalli R, Chu Z, Li X. Diffusion tensor imaging of mild to moderate blast-related traumatic brain injury and its sequelae. J Neurotrauma. 2010; 27:683-94. [PubMed: 20088647]

Lighthall JW, Dixon CE, Anderson TE. Experimental models of brain injury. J Neurotrauma. 1989; 6:83-97. [PubMed: 2671392] 
Long JB, Bentley TL, Wessner KA, Cerone C, Sweeney S, Bauman RA. Blast overpressure in rats: recreating a battlefield injury in the laboratory. J Neurotrauma. 2009; 26:827-40. [PubMed: 19397422]

Longhi L, Saatman KE, Fujimoto S, Raghupathi R, Meaney DF, Davis J, McMillan BSA, Conte V, Laurer HL, Stein S, Stocchetti N, McIntosh TK. Temporal window of vulnerability to repetitive experimental concussive brain injury. Neurosurgery. 2005; 56:364-74. [PubMed: 15670384]

Mac Donald CL, Johnson AM, Cooper D, Nelson EC, Werner NJ, Shimony JS, Snyder AZ, Raichle ME, Witherow JR, Fang R, Flaherty SF, Brody DL. Detection of blast-related traumatic brain injury in U.S. military personnel. New Eng J Med. 2011; 364:2091-100. [PubMed: 21631321]

Marmarou A, Foda MA, van den Brink W, Campbell J, Kita H, Demetriadou K. A new model of diffuse brain injury in rats. Part I: Pathophysiology and biomechanics. J Neurosurg. 1994; 80:291300. [PubMed: 8283269]

Masada T, Hua Y, Xi G, Ennis SR, Keep RF. Attenuation of ischemic brain edema and cerebrovascular injury after ischemic preconditioning in the rat. J Cereb Blood Flow Metab. 2001; 21:22-33. [PubMed: 11149665]

Masel BE, DeWitt DS. Traumatic brain injury: a disease process, not an event. J Neurotrauma. 2010; 27:1529-40. [PubMed: 20504161]

McKee AC, Cantu RC, Nowinski CJ, Hedley-Whyte ET, Gavett BE, Budson AE, Santini VE, Lee HS, Kubilus CA, Stern RA. Chronic traumatic encephalopathy in athletes: progressive tauopathy after repetitive head injury. J Neuropathol Exp Neurol. 2009; 68:709-35. [PubMed: 19535999]

McKee AC, Gavett BE, Stern RA, Nowinski CJ, Cantu RC, Kowall NW, Perl DP, Hedley-Whyte ET, Price B, Sullivan C, Morin P, Lee HS, Kubilus CA, Daneshvar DH, Wulff M, Budson AE. TDP-43 proteinopathy and motor neuron disease in chronic traumatic encephalopathy. J Neuropathol Exp Neurol. 2010; 69:918-29. [PubMed: 20720505]

Meaney DF, Smith DH. Biomechanics of concussion. Clin Sports Med. 2011; 30:19-31. [PubMed: 21074079]

Milman A, Rosenberg A, Weizman R, Pick CG. Mild traumatic brain injury induces persistent cognitive deficits and behavioral disturbances in mice. J Neurotrauma. 2005; 22:1003-10. [PubMed: 16156715]

Morales DM, Marklund N, Lebold D, Thompson HJ, Pitkanen A, Maxwell WL, Longhi L, Laurer H, Maegele M, Neugebauer E, Graham DI, Stocchetti N, McIntosh TK. Experimental models of traumatic brain injury: do we really need to build a better mousetrap? Neuroscience. 2005; 136:971-89. [PubMed: 16242846]

Okie S. Traumatic brain injury in the war zone. N Engl J Med. 2005; 352:2043-7. [PubMed: 15901856]

Omalu BI, Hamilton RL, Kamboh MI, DeKosky ST, Bailes J. Chronic traumatic encephalopathy (CTE) in a National Football League Player: Case report and emerging medicolegal practice questions. J Forensic Nurs. 2010; 6:40-6. [PubMed: 20201914]

Park HK, Fernandez II, Dujovny M, Diaz FG. Experimental animal models of traumatic brain injury: medical and biomechanical mechanism. Crit Rev Neurosurg. 1999; 9:44-52. [PubMed: 9933368]

Pellman EJ, Viano DC, Casson IR, Tucker AM, Waeckerle JF, Powell JW, Feuer H. Concussion in professional football: repeat injuries--part 4. Neurosurgery. 2004; 55:860-73. [PubMed: 15458594]

Pellman EJ, Viano DC, Tucker AM, Casson IR. Concussion in professional football: location and direction of helmet impacts-Part 2. Neurosurgery. 2003a; 53:1328-40. [PubMed: 14633299]

Pellman EJ, Viano DC, Tucker AM, Casson IR, Waeckerle JF. Concussion in professional football: reconstruction of game impacts and injuries. Neurosurgery. 2003b; 53:799-812. [PubMed: 14519212]

Planel E, Richter KE, Nolan CE, Finley JE, Liu L, Wen Y, Krishnamurthy P, Herman M, Wang L, Schachter JB, Nelson RB, Lau LF, Duff KE. Anesthesia leads to tau hyperphosphorylation through inhibition of phosphatase activity by hypothermia. J Neurosci. 2007; 27:3090-7. [PubMed: 17376970]

Plassman BL, Havlik RJ, Steffens DC, Helms MJ, Newman TN, Drosdick D, Phillips C, Gau BA, Welsh-Bohmer KA, Burke JR, Guralnik JM, Breitner JC. Documented head injury in early 
adulthood and risk of Alzheimer's disease and other dementias. Neurology. 2000; 55:1158-66. [PubMed: 11071494]

Pullela R, Raber J, Pfankuch T, Ferriero DM, Claus CP, Koh SE, Yamauchi T, Rola R, Fike JR, Noble-Haeusslein LJ. Traumatic injury to the immature brain results in progressive neuronal loss, hyperactivity and delayed cognitive impairments. Dev Neurosci. 2006; 28:396-409. [PubMed: 16943663]

Rutland-Brown W, Langlois JA, Thomas KE, Xi YL. Incidence of traumatic brain injury in the United States, 2003. J Head Trauma Rehabil. 2006; 21:544-8. [PubMed: 17122685]

Schumann J, Alexandrovich GA, Biegon A, Yaka R. Inhibition of NR2B phosphorylation restores alterations in NMDA receptor expression and improves functional recovery following traumatic brain injury in mice. J Neurotrauma. 2008; 25:945-57. [PubMed: 18721106]

Stahel PF, Shohami E, Younis FM, Kariya K, Otto VI, Lenzlinger PM, Grosjean MB, Eugster HP, Trentz O, Kossmann T, Morganti-Kossmann MC. Experimental closed head injury: analysis of neurological outcome, blood-brain barrier dysfunction, intracranial neutrophil infiltration, and neuronal cell death in mice deficient in genes for pro-inflammatory cytokines. J Cereb Blood Flow Metab. 2000; 20:369-80. [PubMed: 10698075]

Statler KD, Alexander H, Vagni V, Holubkov R, Dixon CE, Clark RS, Jenkins L, Kochanek PM. Isoflurane exerts neuroprotective actions at or near the time of severe traumatic brain injury. Brain Res. 2006; 1076:216-24. [PubMed: 16473332]

Tanielian, T.; Jaycox, LH., editors. Invisible Wounds of War: Psychological and Cognitive Injuries, Their Consequences, and Services to Assist Recover. RAND Corporation; Santa Monica, CA: 2008.

Thomas DM, Francescutti-Verbeem DM, Kuhn DM. Increases in cytoplasmic dopamine compromise the normal resistance of the nucleus accumbens to methamphetamine neurotoxicity. J Neurochem. 2009; 109:1745-55. [PubMed: 19457119]

Thomas DM, Francescutti-Verbeem DM, Kuhn DM. Methamphetamine-induced neurotoxicity and microglial activation are not mediated by fractalkine receptor signaling. J Neurochem. 2008a; 106:696-705. [PubMed: 18410508]

Thomas DM, Francescutti-Verbeem DM, Kuhn DM. The newly synthesized pool of dopamine determines the severity of methamphetamine-induced neurotoxicity. J Neurochem. 2008b; 105:605-16. [PubMed: 18088364]

Thomas DM, Walker PD, Benjamins JA, Geddes TJ, Kuhn DM. Methamphetamine neurotoxicity in dopamine nerve endings of the striatum is associated with microglial activation. J Pharmacol Exp Ther. 2004; 311:1-7. [PubMed: 15163680]

Thompson HJ, Lifshitz J, Marklund N, Grady MS, Graham DI, Hovda DA, McIntosh TK. Lateral fluid percussion brain injury: a 15-year review and evaluation. J Neurotrauma. 2005; 22:42-75. [PubMed: 15665602]

Uryu K, Laurer H, McIntosh T, Pratico D, Martinez D, Leight S, Lee VM, Trojanowski JQ. Repetitive mild brain trauma accelerates Abeta deposition, lipid peroxidation, and cognitive impairment in a transgenic mouse model of Alzheimer amyloidosis. J Neurosci. 2002; 22:446-54. [PubMed: 11784789]

Van Boven RW, Harrington GS, Hackney DB, Ebel A, Gauger G, Bremner JD, D’Esposito M, Detre JA, Haacke EM, Jack CR Jr. Jagust WJ, Le Bihan D, Mathis CA, Mueller S, Mukherjee P, Schuff $\mathrm{N}$, Chen A, Weiner MW. Advances in neuroimaging of traumatic brain injury and posttraumatic stress disorder. J Rehabil Res Dev. 2009; 46:717-57. [PubMed: 20104401]

Viano DC, Casson IR, Pellman EJ. Concussion in professional football: biomechanics of the struck player--part 14. Neurosurgery. 2007; 61:313-27. [PubMed: 17762744]

Viano DC, Casson IR, Pellman EJ, Bir CA, Zhang L, Sherman DC, Boitano MA. Concussion in professional football: comparison with boxing head impacts--part 10. Neurosurgery. 2005; 57:1154-72. [PubMed: 16331164]

Viano DC, Hamberger A, Bolouri H, Saljo A. Concussion in professional football: animal model of brain injury--part 15. Neurosurgery. 2009; 64:1162-73. [PubMed: 19487897]

Viano DC, Pellman EJ. Concussion in professional football: biomechanics of the striking player--part 8. Neurosurgery. 2005; 56:266-80. [PubMed: 15670375] 
Weber JT. Experimental models of repetitive brain injuries. Prog Brain Res. 2007; 161:253-61. [PubMed: 17618983]

Zohar O, Schreiber S, Getslev V, Schwartz JP, Mullins PG, Pick CG. Closed-head minimal traumatic brain injury produces long-term cognitive deficits in mice. Neuroscience. 2003; 118:949-55.

[PubMed: 12732240] 


\section{Highlights}

- Development of a new model of human repetitive mild TBI using mice as subjects

- Method can be used repetitively to impart diffuse closed-head injury without causing skull fracture, intracranial bleeding or seizures

- Neurological and behavioral effects are mild and show recovery over time

- Histopathological findings are consistent with analysis of postmortem human brains from individuals suffering multiple, mild concussive injuries

- Model overcomes constraints on existing animal models of TBI to allow characterization of the pathophysiology of repetitive mild TBI 


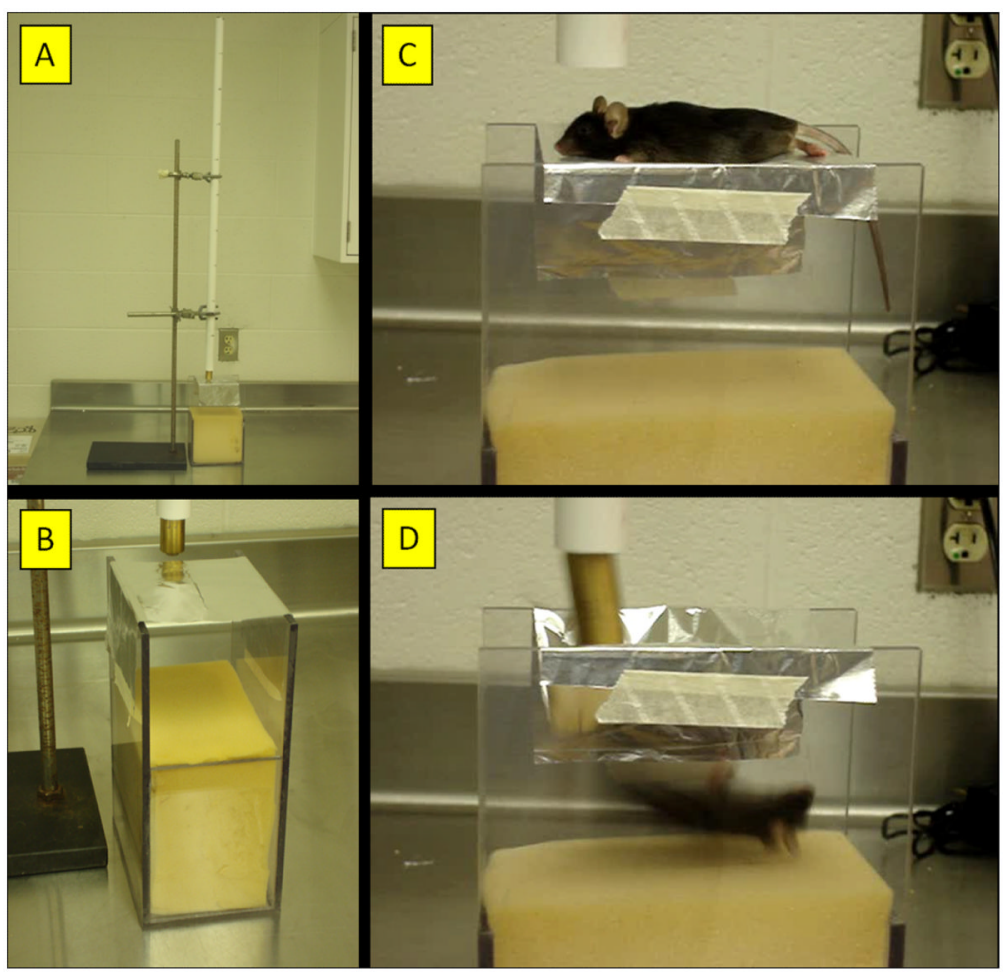

Fig. 1.

Apparatus for rmTBI using the mouse as subject. The essential components of the apparatus are shown and depict (A) a photograph of the entire assembly comprised of a vertical guide tube for the dropped weight situated above the mouse stage and collecting sponge; (B) a photograph of the slit aluminum sheet that serves as the mouse stage above the collecting sponge; (C) a still captured from a video recording showing the positioning of the mouse on the stage immediately prior to head impact by the falling weight; and (D) a still captured from a video showing the mouse approximately $30 \mathrm{msec}$ after head impact, illustrating the resulting $180^{\circ}$ rotation of the mouse after head impact and ensuing acceleration/rotation. 


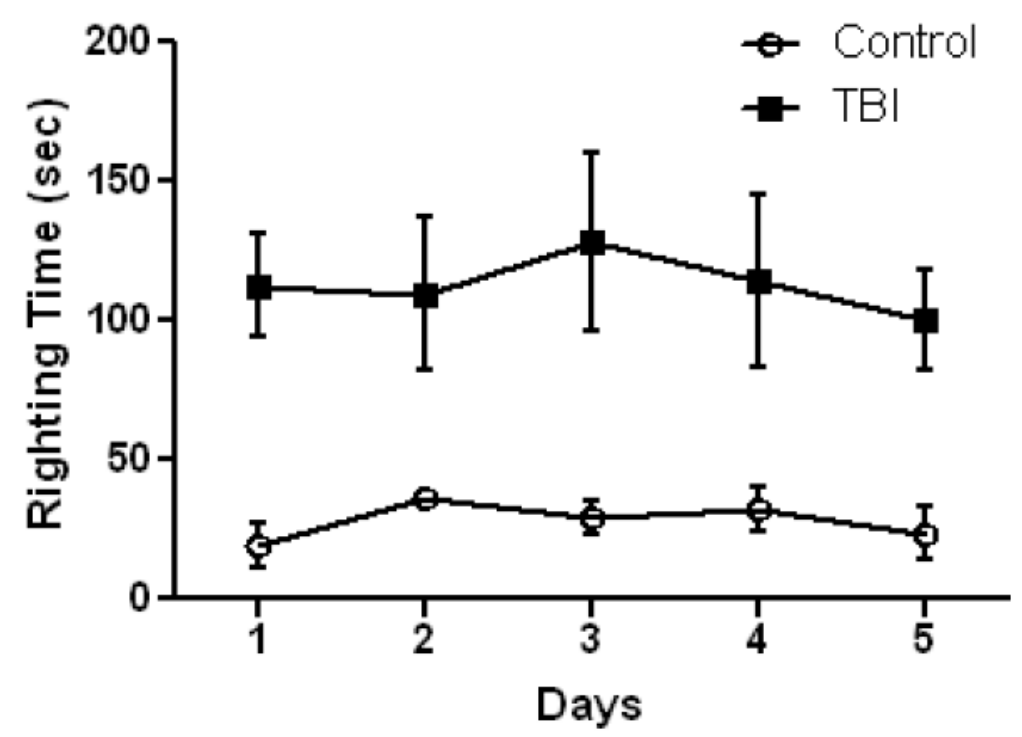

Fig. 2.

Recovery of righting reflex after TBI. Mice ( $N=12$ /group) were exposed to the indicated number of head impacts on successive days using the new model of rmTBI and the time to recover the righting reflex was recorded. Controls were anesthetized but not subjected to head injury. Results are mean \pm SEM of the time (in seconds) required for mice to right themselves after anesthesia \pm TBI. The main effect of treatment on recovery of the righting reflex was significant ( $<<0.001,2$-way ANOVA). The within group effect of days was not significant for either group. 


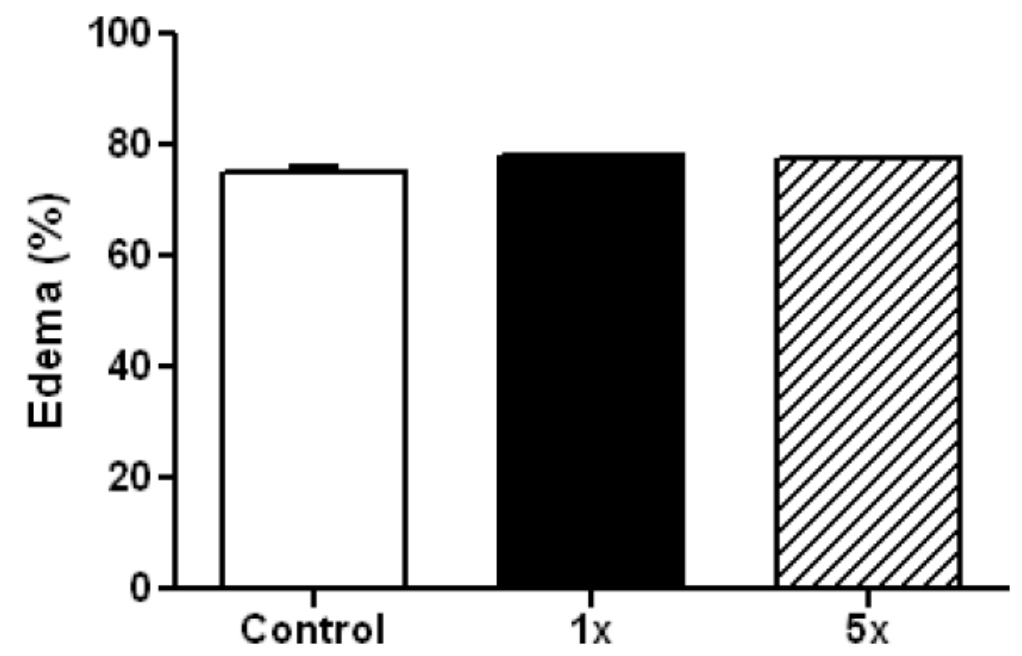

Fig. 3.

rmTBI does not result in edema formation. Controls $(\mathrm{N}=6)$ and mice $(\mathrm{N}=6)$ exposed to the indicated number of head impacts using the new model of rmTBI were sacrificed and edema was determined by the wet/dry method $4 \mathrm{hr}$ after the last injury. Results are means \pm SEM of brain water content calculated as (wet weight - dry weight $) /($ wet weight $) \times 100$. 


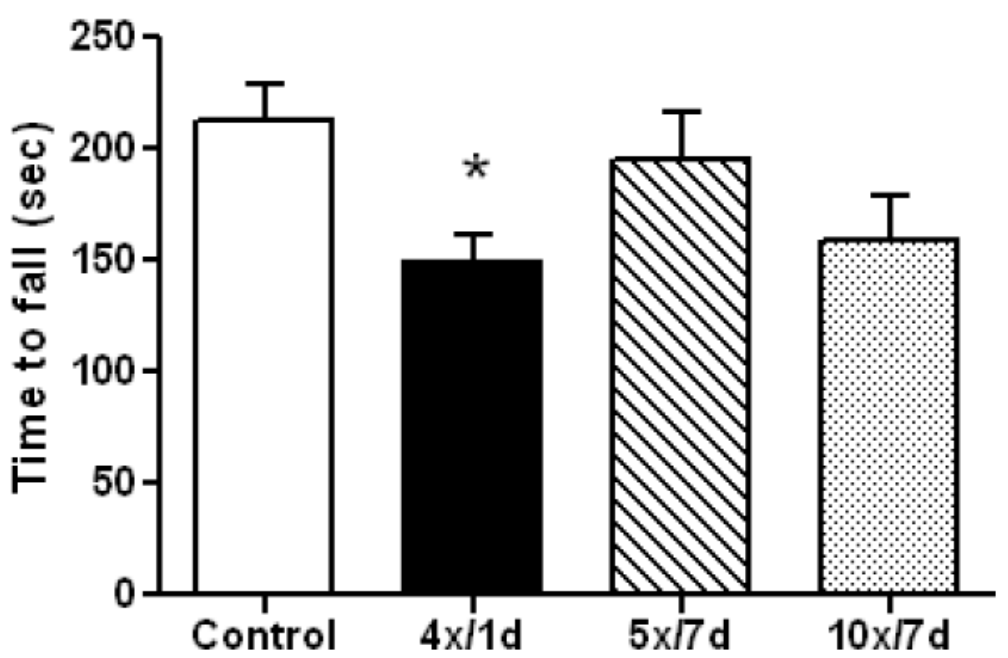

Fig. 4.

Effect of rmTBI on rotarod performance. Controls $(\mathrm{N}=21)$ and mice exposed to $4(\mathrm{~N}=7), 5$ $(\mathrm{N}=11)$ or $10(\mathrm{~N}=10)$ head impacts were tested for balance and coordination on the accelerating rotarod at the indicated times (in days) after the last injury. Results are the mean \pm SEM of the time subjects remained on the rotarod before falling. The symbol $*$ indicates that deficits were significantly different from control $(\mathrm{p}<0.05)$. 


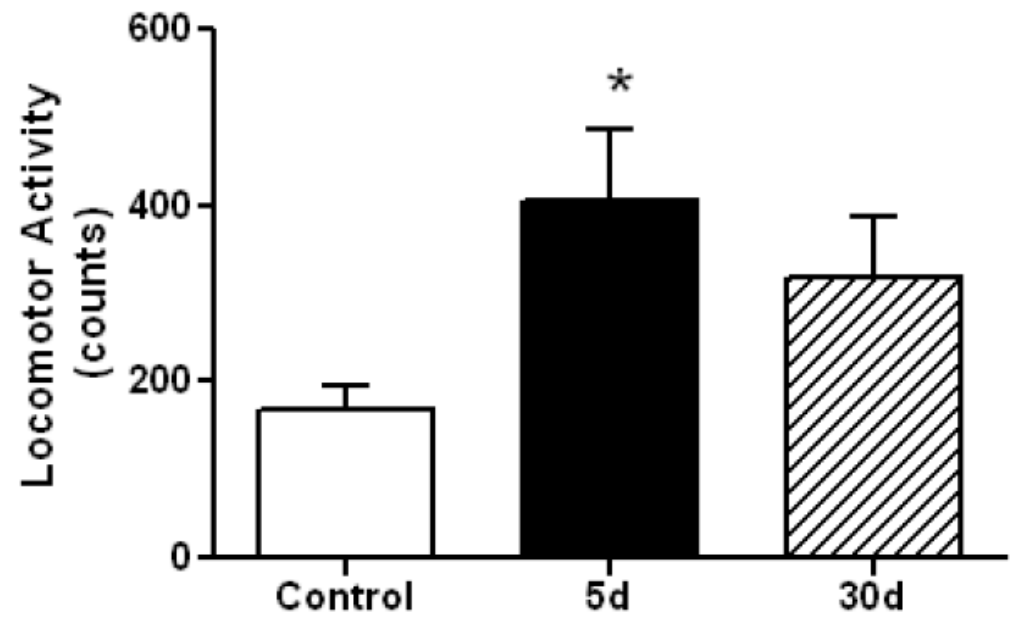

Fig. 5.

Effect of rmTBI on locomotor activity. Controls $(\mathrm{N}=6)$ and mice $(\mathrm{N}=6)$ exposed to 5 head impacts (1/day for 5 successive days) were tested for locomotor activity 5 or 30 days after the last injury. Horizontal and vertical activity was recorded in an automated apparatus as mouse movement interrupted infrared beams of light. Results are the mean \pm SEM of activity counts captured in a $30 \mathrm{~min}$ test session. The symbol $*$ indicates a significant difference from controls $(\mathrm{p}<0.05)$. 

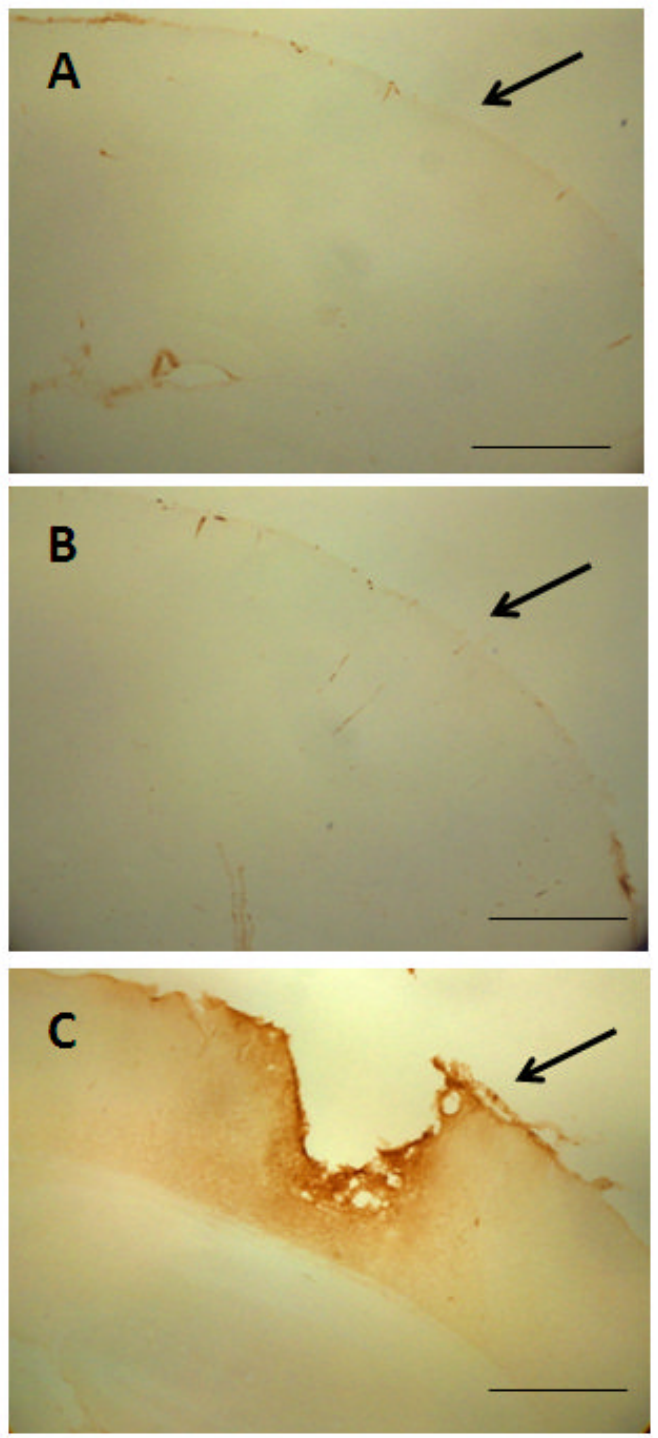

Fig. 6.

Effect of rmTBI on integrity of the blood brain barrier. Controls (A) or mice (B) subjected to 5 head impacts (1/day for 5 successive days) were perfused 7 days after the last injury and the integrity of the blood brain barrier was assessed by immunohistochemical analysis of intracerebral levels of mouse IgG. Panel (C) shows a representative image from a mouse 7 days after exposure to a single head impact using the original Marmarou method. Because IgG immunoreactivity in brains of mice subjected to the new method of rmTBI was so low, arrows are inserted to demarcate the surface of the cortex below the site of skull impact. The calibration bar represents $50 \mathrm{um}$. 
A
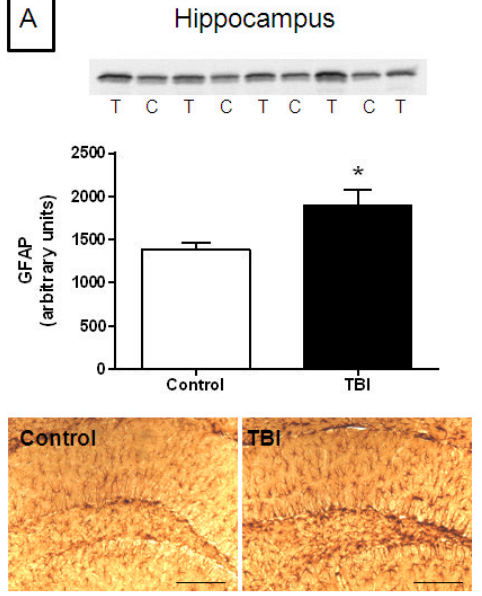
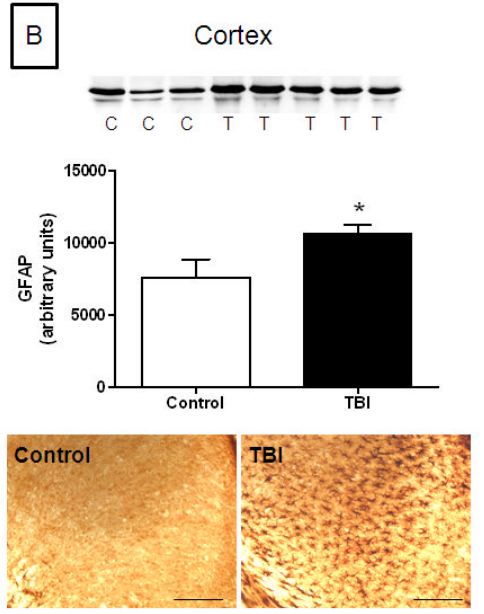

Fig. 7.

Effect of rmTBI on GFAP expression. Controls or mice exposed to 10 head impacts using the new method of rmTBI were analyzed for GFAP expression by immunoblotting (upper panels) or in 50 um fixed sections by immunohistochemistry (lower panels) in hippocampus (A) or cortex (B) 7 days after the last treatment. Each lane on the immunoblots represents individual control (C) or rmTBI-treated (T) mice. Data for the bar charts was derived from scans of immunoblots using ImageJ. The symbol * indicates a significant difference from control $(\mathrm{p}<0.05)$. The calibration bar represents $50 \mathrm{um}$. 

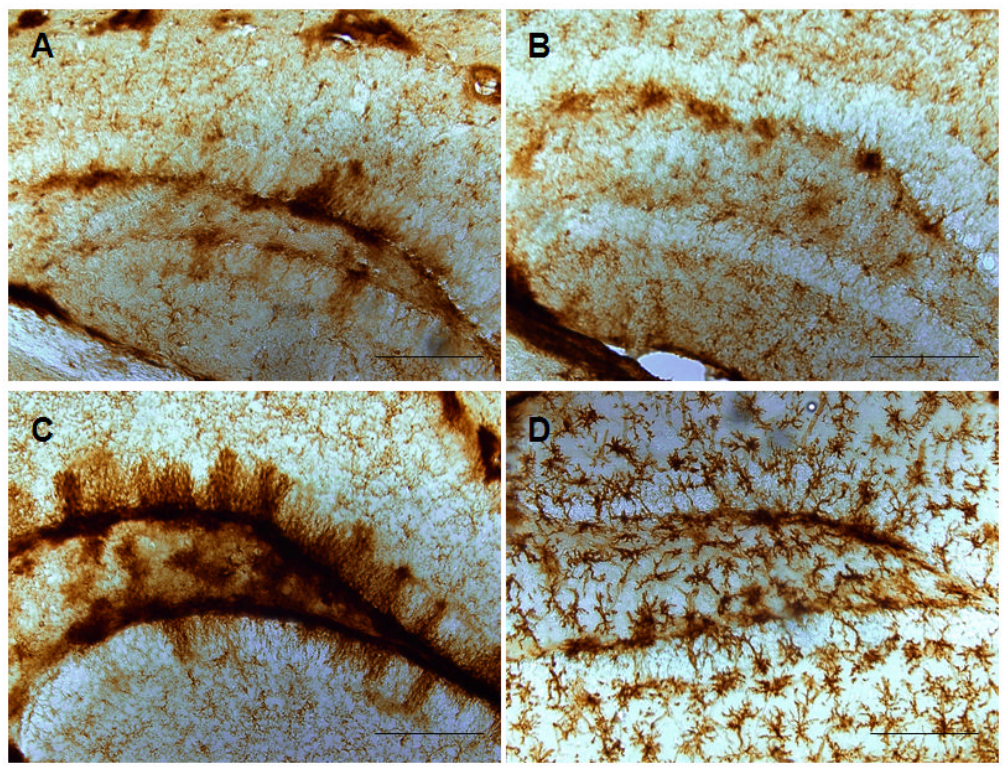

Fig. 8.

rmTBI does not result in microglial activation. Paraformaldehyde-fixed sections (50 um) from controls (A) or mice exposed to 5 (B) or 10 (C) head impacts using the new method or to a single impact using the original Marmarou method (D) were analyzed for microglial activation using $\mathrm{ILB}_{4}$ histochemical staining. The calibration bar represents $50 \mathrm{um}$. 

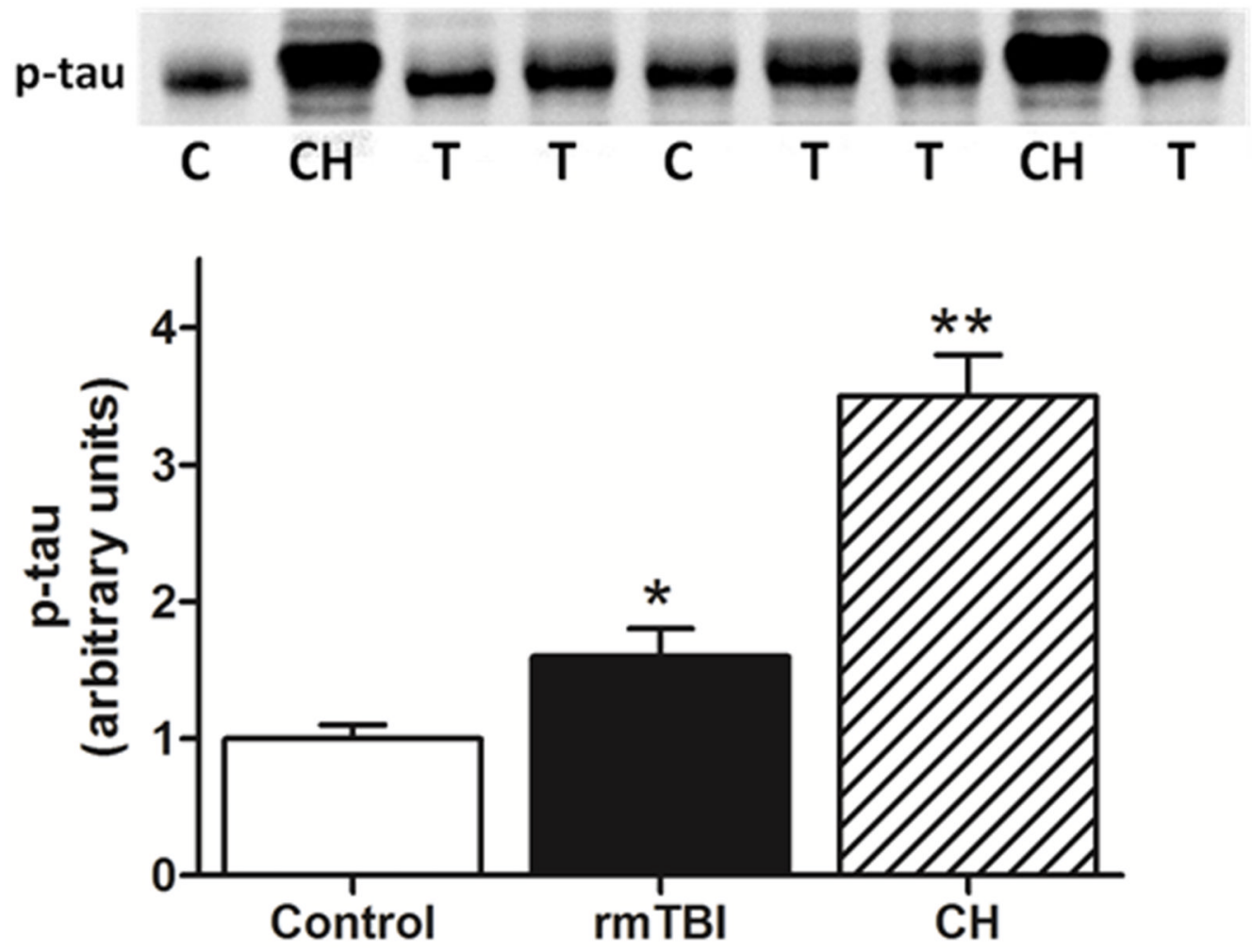

Fig. 9.

Increased phospho-tau after rmTBI. Controls or mice exposed to 5 head impacts (1/day for 5 successive days) were tested for phospho-tau by immunoblotting 30 days after the last treatment. Bands on the blot represent individual controls (C) or mice exposed to rmTBI (T). As a positive control, mice were also treated with chloral hydrate $(\mathrm{CH} ; 500 \mathrm{mg} / \mathrm{kg}$, ip) which is known to cause hyper-phosphorylation of tau. The symbols indicate significant differences from control with $\mathrm{p}<0.05(*)$ or $0.001(* *)$. 
Table 1

Comparison of a new rmTBI model with the original Marmarou weight drop method

\begin{tabular}{|l|c|c|c|}
\hline & rmTBI- 1X & rmTBI-5X & Original Marmarou-1X \\
\hline Mortality & $5 \%$ & $10 \%$ & $60 \%^{a}$ \\
\hline Neither bleed nor fracture & $90 \%$ & $90 \%$ & $20 \%$ \\
\hline Skull fracture & $0 \%$ & $0 \%$ & $10 \%$ \\
\hline Bleed & $10 \%$ & $10 \%$ & $10 \%$ \\
\hline Both bleed and fracture & $0 \%$ & $0 \%$ & $60 \%$ \\
\hline
\end{tabular}

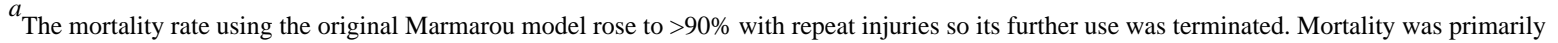
from respiratory arrest. Group sizes were $\mathrm{N}=49$ for the new rmTBI method and $\mathrm{N}=50$ for the original Marmarou method. 